\title{
Phenomena at three-phase electroslag remelting
}

\author{
Zhong-li Liu', *Lev Medovar², Ganna Stovpchenko², Volodymyr Petrenko ${ }^{2}$, Artem Sybir ${ }^{3}$, Yev. Volchenkov ${ }^{2}$ \\ 1. Yantai University, Yantai 264005, Shandong, China \\ 2. E. O. Paton Electric Welding Institute, Kyiv 03180, Ukraine \\ 3. National metallurgical academy of Ukraine, Dnipro 49600, Ukraine
}

\begin{abstract}
The electroslag remelting (ESR) process is widely used to produce high-quality ingots and billets for high-alloyed steels and alloys. Both the single-phase and three-phase alternating current diagram with bifilar and monofilar connection are in use for heavy ingot manufacturing. The numerical simulation of the three-phase bifilar circuit for the $120 \mathrm{t}$ three-phase bifilar six-electrode ESR furnace at different variants of electric connection was presented and discussed. At the bifilar diagram of power supply, the geometrical location of electrodes in a mould holds critical importance for performances: the close location of bifilar pair electrodes provides the highest heat productivity, but the equidistant location of electrodes gives a much more uniform heat distribution. The monofilar mulit-electrode diagram of three-phase connection without phase shift shows the most uniform distribution of potential and heat generation as well as a favorable magnetic field that makes this kind the most promising for providing a high quality of heavy ingots.
\end{abstract}

Key words: electroslag remelting; three-phase circuit; bifilar; monofilar; simulation; heavy ingot
CLC numbers: TP391.9
Document code: $\mathrm{A}$
Article ID: 1672-6421(2021)06-557-08

\section{Introduction}

The widespread use of the electroslag remelting (ESR) process has grown significantly in recent years, making it the most employed process for special melting, primarily for the manufacturing of ingots from sophisticated steel grades and high-performance alloys, especially heavy ingots. At present, the global ESR steel output is about 3 million tons, which is much less than the common steel output each year, however, it grows steadily in line with the increase in customer demand for high-quality steels and products. The ESR process characterizes both ingot quality and metal yield, however, it is also a power-intensive process. It is clear that electric current is the main driving force of the ESR process, and, equally clear, the price of electricity is growing year by year. For more than 55 years of commercial application, a large number of options for current supply to an electrode, ingot and in some cases to a slag bath, were investigated, but the final decision in favor of the only single circuit variant of power supply at the ESR has not yet been made. To date, there are many unclear and controversial

\section{*Lev Medovar}

Male, born in 1954, Ph.D., Professor. His research interests mainly focus on ESR technology and equipment improvement.

E-mail: medovar@elmet-roll.com.ua

Received: 2021-01-19; Accepted: 2021-09-15 suggestions on the advantages and disadvantages of the most common ways to supply electric current for the ESR. Recently, the attention of many experts in this field has focused on improving the technologies and design of ESR furnaces for manufacturing heavy ingots over $100 \mathrm{t}$ in weight. This challenge comes due to the increasing demand for high-quality heavy forgings for power generation and petrochemistry industries. Any new knowledge helping to increase energy savings at the ESR is of utmost importance and contributes to the sustainable development of the metallurgical industry. Two principal diagrams for current supply are the most common for such ESR furnaces: monofilar circuit and three-phase bifilar circuit. For ESR ingots more than $100 \mathrm{t}$, two famous ESR furnace manufacturing factories, i.e., INTECO of Austria and CONSARC from the USA, focus on monofilar mode, and the maximum capacity is 250 t. However, China used a different method where three-phase and three-phase bifilar six-electrode were adopted to produce heavy ingots. For the overseas model, it is easier to realize gas protection, and for the Chinese model, the electrode is easier to produce, moreover, electricity consumption is less.

\section{State of the art}

Today, the most common energy supply system is the three-phase system with sinusoidal EMFs of the same frequency shifted in phase by a certain angle, 
which ensures the efficiency of electric power transmission and the possibility of creating a rotating magnetic field, and at the same time, three-phase system makes possible the work of motors (synchronous, asynchronous and linear), and other electrical devices. Moreover, most metallurgical workshops are connected mainly to the three-phase grid worldwide. However, historically, the first commercial ESR furnace was built in the former USSR by process inventors Academicians Paton and Borys Medovar ${ }^{[1]}$ with one consumable electrode and fed by single-phase alternating current supplied by a special transformer from a three-phase electric network. Starting from the ESR process invention, the single-phase monofilar diagram of power supply [Fig. 1(a)] was, and still is, the most widespread for the ESR furnaces.

Single electrode configuration provides a high filling ratio, which could reach $0.6-0.7$ (ratio of cross-section area). This feature has two consequences: positive - at greater filling ratio it is possible to melt with lower rate and the depth of the liquid metal pool is less; and negative - the production of high-quality electrodes of a large cross-section is difficult and expensive. Otherwise, the ESR ingot substantially inherits segregation from the consumable electrode. The monofilar connections of many smaller electrodes are also the way, but more welding work would increase the cost.

The ESR under monofilar connection [Fig. 1(a)] alternating current mostly runs in the circuit: transformer - high current loop - consumable electrode - molten slag - growing ingot bottom plate - high current loop - transformer. At the monofilar connection, there are two long parts (upper and lower lines) of high current loop carrying the same load. Each part of the high current loop of the monofilar furnace must ensure the passage of large current, which requires the use of large sections of copper busbars and water cooling of the cables to avoid their heating and connected losses. Usually, the ESR transformer located in a place allowing to equalise both lines' length to minimize the inductive contour and reduce loss caused by impedance. As a result, the specific energy consumption for modern single-phase one electrode electroslag furnaces is $1,100-1,500 \mathrm{kWh}$ per ton of ingot (ingots of $1.5 \mathrm{~m}$ in diameter and less).

The heat of single-phase releases in a slag along a ring, which is formed by the surface of the electrode and relatively thin adjacent layer due to the skin effect (reduction of an effective cross-section of the conductor) at the alternative current running. The part of the current goes through the growing ingot and heats the liquid metal pool, thus increasing its depth. Besides, any single-phase consumer in the three-phase supplying system will load the network unevenly and worsen the work of other energy consumers. At the single-phase load, the $\cos \varphi$ is usually increased by introducing a capacitance or additional variable resistance to compensate for the inductance but the losses of electric energy are unavoidable. Modern, powerful ESR furnaces would produce a lot of harmonics and flickers in the supplying network. Therefore, the high power compensating devices are in use for the ESR furnace to reduce a disturbance to the network.
From the very beginning, Chinese engineers have realized this problem and have started to use three-phase ESR furnaces, which reduce the side effects of single-phase load inherent to the monofilar ESR furnaces in the supplying three-phase network. Figure 1 schematically shows the diagram of single-phase monofilar [Fig. 1(a)] and bifilar [Fig. 1(b)] furnaces and threephase multi-electrode monofilar [Fig. 1(c)] and bifilar [Fig. 1(d)] furnaces, which were simulated and compared in this study.

Bifilar configuration for ESR furnace power supply, as shown in Figs. 1(b) and (d), provides a shorter connection of high current loop via molten slag between electrodes: "transformer - one consumable electrode - liquid slag bath slag - second consumable electrode - transformer". In some cases, current can go through the liquid metal bath coming from and going back to the slag bath. The eventual current load in the circuit "electrode - slag - mould - bottom plate - ingot - slag - second electrode" appears at imbalance in bifilar pairs only (imbalance arises at the great difference in electrical resistivity between electrodes in the bifilar pair). It is much less compared to the monofilar connection.

At single-phase bifilar connections there are two different "pole" electrodes, and the way of current between them is much shorter. At a three-phase bifilar connection, the number of electrodes must be a multiple of two and three, and, accordingly, the minimum number of electrodes is six. The placement of six electrodes in a cylindrical mould (maintaining critical distances to its wall and between the electrodes) determines a low filling ratio (0.15-0.35). The electrodes of smaller cross-section become much longer or more times of electrodes exchange while melting is necessary. Smaller electrodes melt faster than a big section single electrode. The high melting rate provides a good surface of the ESR ingot but increases the depth of the liquid metal pool.

The connection between electrodes in a three-phase bifilar furnace is more sophisticated than in a single-phase one. Symmetric and short high current loop at the bifilar connection provides minimum inductive losses (power factor comes to $0.99)$. Specific power consumption is about $60 \%-80 \%$ of the value for single-phase single electrode ESR furnace for the same ingot. The bifilar connection easily causes a "short leg" phenomenon when one consumable electrode with shrinkage inside melts faster, provoking an imbalance in current distribution and current arising in the "zero cable". This phenomenon is one of the reasons inhibiting the widespread use of bifilar furnaces, but it is possible to overcome using a separate motor for each electrode. Another inhibition is the difficulties in designing the electrodes change and gas protection using the close chamber.

The three-phase monofilar ESR furnace having three consumable electrodes connected to each phase is easier to be realized and controlled. In this case, the upper part of the high current loop is more complicated than at the single-phase monofilar and in the lower part - the same this variant has. The electric current here is also going through the whole ingot [as shown in Fig. 1(a) for analogous single-phase monofilar 
(a)

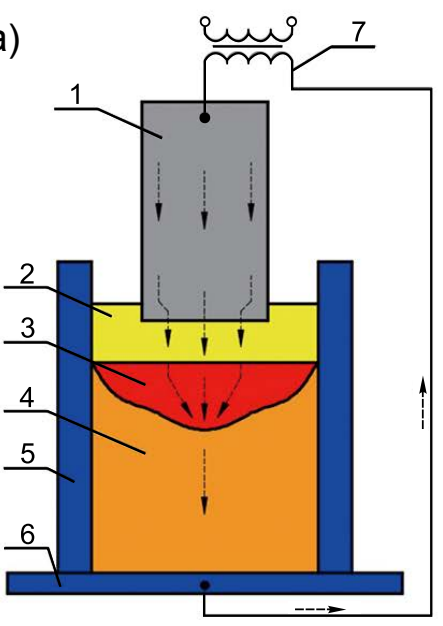

(c)

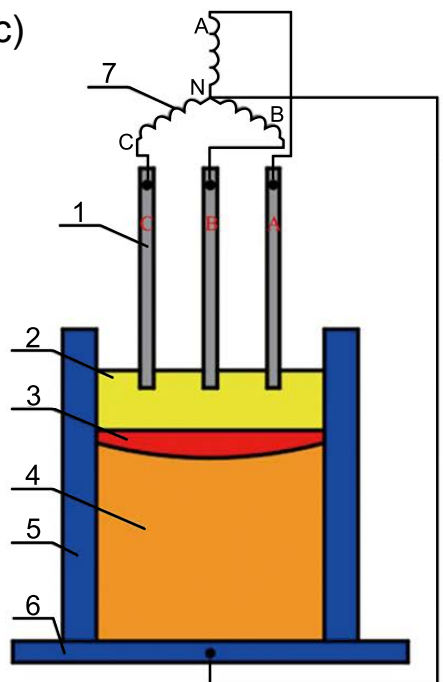

(b)

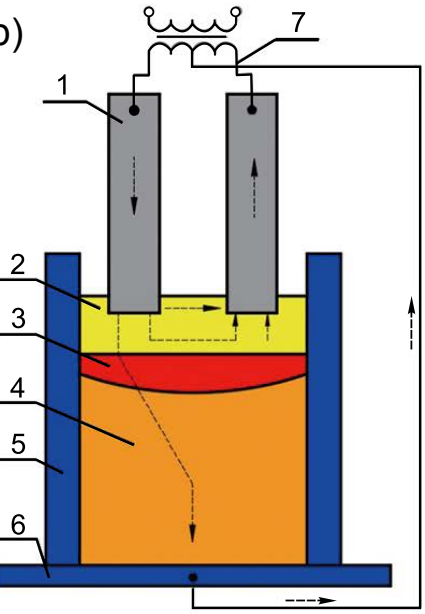

(d)

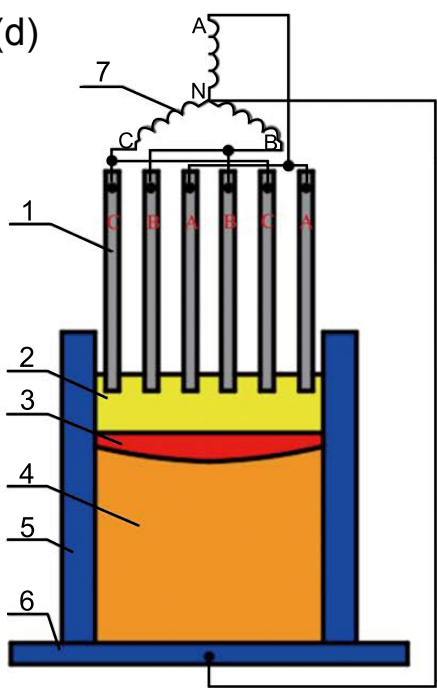

Fig. 1: Diagrams of single-phase one electrode monofilar (a) and bifilar (b), three-phase multielectrode monofilar (c) and three-phase bifilar (d) of ESR (1- consumable electrode, 2- molten slag, 3- molten pool, 4- solidified ingot, 5- water-cooled mould, 6- water-cooled base plate, 7- power source)

increasing a depth of the liquid metal (factor of ingots quality) ${ }^{[2]}$.

There are several recent articles discussing the results of simulation of magneto dynamic and heat processes for bifilar and multielectrode ESR. Researchers ${ }^{[3]}$ have made a simulation of a three-phase ESR furnace using a proprietary ESR3D program to enmesh the solid model for a 80-120 $t$ ingot and related equipment. The calculation results were of assistance in optimizing the ESR process to produce a large ingot that satisfied nuclear industry requirements.

A 3D finite-element model (FEM) was developed to understand the electromagnetic field and liquid metal pool shape in the electroslag remelting process with two seriesconnected electrodes ${ }^{[4]}$. In another study ${ }^{[5]}$, the threedimensional (3D) finite element model was developed to simulate the electromagnetic field and temperature field for a system of an electrode, slag and ingot in the ESR system with three-phase installation. The FEM was applied to simulate the electromagnetic field and Joule heating in the ESR system with three electrodes ${ }^{[6]}$. Peculiarities were discovered in the triple-electrode ESR concerning the formation of metal droplets and the solidification of liquid metal by Ren et al ${ }^{[7]}$.
However, despite such visible preferences given by the bifilar diagram, these furnaces are mainly used in China ${ }^{[8]}$, and for the production of flat (slab) and hollow ingots in other countries ${ }^{[9-11]}$. The majority of manufacturers in Europe and the United States design the ESR furnace using single-phase power source and monofilar connection of one consumable electrode ${ }^{[12-14]}$. From the point of view of efficiency, a shorter high current loop and compensating device absence make design easier. Both the cost of furnace installation and electrical loss at operation are less, yet the quality of ingot should be no worse. That is why the three-phase and threephase bifilar furnaces for ingot manufacturing are becoming widespread in China. The practice of the operation of Chinese ESR furnaces using a three-phase bifilar power scheme for large ingots is also successful, including the $120 \mathrm{t}$ three-phase ESR design supervised for this study ${ }^{[15]}$. However, the answer to the question about the effectiveness of bifilar three-phase circuit at the ESR and its abilities to reduce a depth of the liquid metal pool drove the decision to simulate the electrical current passes and Joule heat distribution for the actual three-phase bifilar $120 \mathrm{t}$ ESR furnace. 


\section{Precondition of simulation}

For numerical experiments, simplified solid-state computer models were built in SolidWorks for real three-phase bifilar six electrodes $120 \mathrm{t}$ ESR furnace. The model consists of steel electrodes, slag bath, ingot, water-cooled copper mould and the bottom plate. The slag skull on the walls of the mould and side surfaces of the electrodes was not considered.

The simulated $120 \mathrm{t}$ ESR furnace has six consumable electrodes connected in three bifilar pairs which are changed pairwise while melting. There are three single-phase transformers of 4,200 kVA each providing secondary voltage 76-128 V and maximal current $32.8 \mathrm{kA}$. The transformers (labelled $\operatorname{Tr} 1, \operatorname{Tr} 2, \operatorname{Tr} 3$ ) are connected in a "star" formation. Each pair of consumable electrodes is connected to each corresponding transformer in a bifilar pattern (designated A1 and $\mathrm{A} 2, \mathrm{~B} 1$ and $\mathrm{B} 2, \mathrm{C} 1$ and $\mathrm{C} 2$, respectively). The principal electric diagram is presented in Fig. 2 below. The midpoint of each transformer is shown as " 0 " and all of them are connected to the bottom plate.

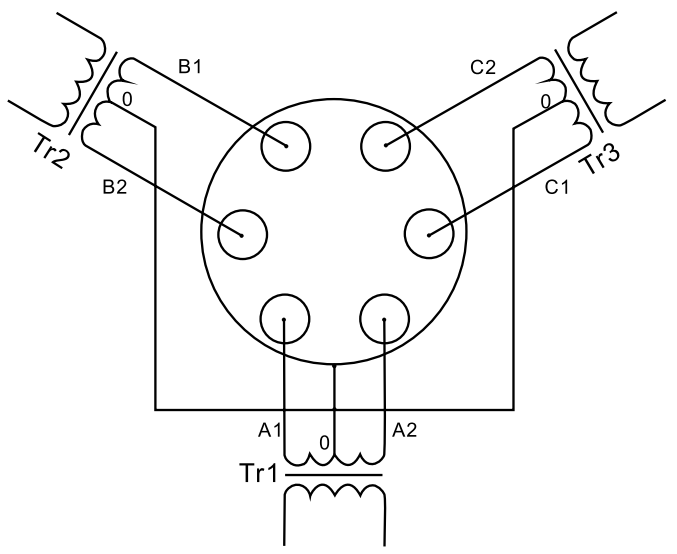

Fig. 2: Electrical diagram of three-phase bifilar ESR $120 \mathrm{t}$ furnace with six consumable electrodes

To simplify the calculation process, the design features of the high current loop and auxiliary units were not taken into account. The 3D model of the studied domain (Fig. 3) was exported to the Comsol Multiphysics software environment for further calculations. In-built mathematical formulas for the

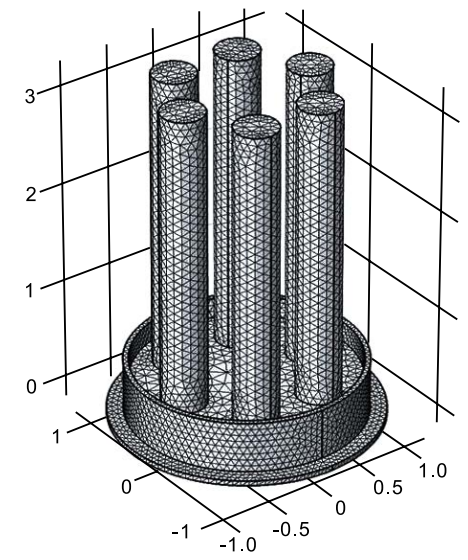

electromagnetic analysis and heat release determination (from the point of the current density and electric conductivity of a slag) were used to simulate the electromagnetic phenomena and Joule heating. The electric and magnetic fields in the ESR are interdependent and are determined by Maxwell's equations and Ohm's law:

$$
\begin{gathered}
\operatorname{curl} \vec{E}=-\frac{\partial(\mu \vec{H})}{\partial \tau} \\
\operatorname{curl} \vec{H}=\vec{J}+\frac{\partial(\vec{D})}{\partial \tau} \\
\operatorname{div} \vec{D}=0 \\
\operatorname{div} \mu \vec{H}=0 \\
\vec{J}=\sigma \vec{E} \\
q_{\mathrm{v}}=\frac{\vec{J} \cdot \vec{J}}{\sigma}
\end{gathered}
$$

where, $\vec{E}$ is the electric field intensity, $\vec{H}$ is the magnetic field intensity, $\vec{J}$ is current density, $\vec{D}$ is the electric flux density, $\mu$ is the permeability of a material, $\sigma$ is the electrical conductivity and $q_{\mathrm{v}}$ is the volumetric power dissipated by Joule effect.

The assumption of model:

- the magnetic Reynolds number is low in the ESR process ${ }^{[16]}$; - the magnetisation is negligible.

The following assumptions and simplifications were also adopted at simulation: all consumable electrodes were identical and had an equal mass and density; imbalance between electrodes was absent, and current to the bottom plate didn't exist. The geometry of the computation domain, electrical parameters and properties of involved materials are given in Table 1.

To understand the nature and characteristics of electromagnetic phenomena and the heat releasing features at the threephase ESR bifilar diagram, the following three variants of the location of the consumable electrodes were studied: the uniform distribution in the mould, and distribution in bifilar pairs of two types - maximum closeness and maximum extension. Figure 3 shows a schematic of the geometric arrangement of the electrodes in a melting space of the ESR furnace for the studied variants, and parameters for the considered variants are listed in Table 2.

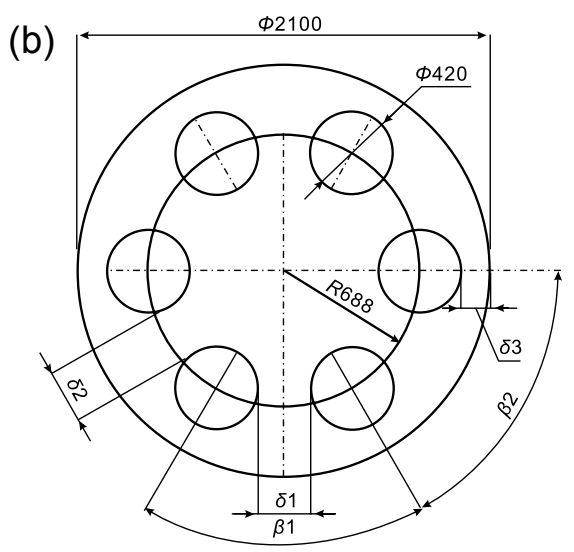

Fig. 3: Geometry of calculated domain (a) and consumable electrodes location in ESR mould (b) 
Table 1: Main geometrical parameters of simulated ESR furnace and materials properties

\begin{tabular}{|c|c|c|}
\hline \multicolumn{2}{|c|}{ Parameters of simulated parts and medias } & Value \\
\hline \multirow{3}{*}{ Slag pool } & Diameter (mm) & 2,100 \\
\hline & Height (mm) & 300 \\
\hline & Slag type & $70 \% \mathrm{CaF}_{2}-30 \% \mathrm{CaO}$ \\
\hline \multirow{5}{*}{ Consumable electrode } & Diameter (mm) & 420 \\
\hline & Length (mm) & 3,000 \\
\hline & Immersion into the slag pool (mm) & 50 \\
\hline & Number, pcs & $3 \times 2$ \\
\hline & Steel grade & AISI 316L \\
\hline \multirow{5}{*}{ Power source } & Number, pcs & 3 \\
\hline & Type of connection & "Star" \\
\hline & Phase shift $\left({ }^{\circ}\right)$ & $0^{\circ}$ and $120^{\circ}$ \\
\hline & Voltage on each bifilar pair (V) & 80 \\
\hline & Frequency $(\mathrm{Hz})$ & 50 \\
\hline \multirow{2}{*}{ Slag } & Electrical conductivity $\left(\mathrm{S} \cdot \mathrm{m}^{-1}\right)$ & 300 \\
\hline & Relative permeability & 30 \\
\hline \multirow{2}{*}{ Steel AISI 316L } & Electrical conductivity $\left(\mathrm{S} \cdot \mathrm{m}^{-1}\right)$ & $8.5 \times 10^{5}$ \\
\hline & Relative permeability & 1 \\
\hline \multirow{2}{*}{ Copper UNS10100 } & Electrical conductivity $\left(\mathrm{S} \cdot \mathrm{m}^{-1}\right)$ & $5.99 \times 10^{7}$ \\
\hline & Relative permeability & 1 \\
\hline
\end{tabular}

Table 2: Simulation matrix with various locations and electrical connection of consumable electrodes

\begin{tabular}{|c|c|c|c|c|c|c|c|c|}
\hline \multirow{2}{*}{ Parameter } & \multicolumn{8}{|c|}{ Value for the variants } \\
\hline & $1-1$ & $1-2$ & $2-1$ & $2-2$ & $3-1$ & $3-2$ & $4-1$ & 4-2 \\
\hline Phase shift, $\varphi$ & $0^{\circ}$ & $120^{\circ}$ & $0^{\circ}$ & $120^{\circ}$ & $0^{\circ}$ & $120^{\circ}$ & $0^{\circ}$ & $120^{\circ}$ \\
\hline $\begin{array}{l}\text { Distance between electrodes of bifilar pair, } \\
\qquad \delta 1(\mathrm{~mm})\end{array}$ & & & & & & & & \\
\hline $\begin{array}{l}\text { Distance between non bifilar electrodes, } \\
\qquad \delta 2(\mathrm{~mm})\end{array}$ & & & & & & & & \\
\hline $\begin{array}{l}\text { Distance between electrode and mould wall, } \\
\qquad \delta 3(\mathrm{~mm})\end{array}$ & & & & & & & & \\
\hline Angle between bifilar electrodes, $\beta 1$ & & & & & & & & \\
\hline $\begin{array}{l}\text { Angle to the neighboring non-bifilar electrode, } \\
\qquad \beta 2\end{array}$ & & & & & & & & \\
\hline
\end{tabular}

The given potential difference between the electrodes is $80 \mathrm{~V}$, and the voltage between the electrode and the bottom plate equals $40 \mathrm{~V}$.

For each of the variants listed in Table 2, the investigation included magnetic flux distribution and the potential differences in the cross-section of the slag bath at $5 \mathrm{~mm}$ distance from the tips of the electrodes (penetration from the surface of the slag bath makes $55 \mathrm{~mm}$ ). 


\section{Simulation results discussion}

The simulation results of potential and magnetic flux density distribution for all simulated variants of electrode locations and possible connections are shown in Fig. 4. The directions of the magnetic flux on the images are indicated by arrows (the bigger the arrow, the greater the intensity). The potentials are shown by color: deep red corresponds to the maximum positive potential, blue is for the maximum negative voltage, and green is zero.

Figure 4 shows the instant situation, and both the potential and magnetic fields pulsate in current frequency $(50 \mathrm{~Hz}$ in this modelling). That means that 50 times per second, the red electrode becomes blue and vice versa, going via intermediate states (good visibility for the phase shift cases). It is essential that all variants of bifilar connection having zero phases shift the magnetic field vectors to form closed circuits bordering each electrode individually (Fig. 4, 1-1, 2-1, 3-1). These magnetic fields would induce slag/metal rotating around each electrode, causing the turbulence in slag bath primarily. This phenomenon favors the high melting rate at the bifilar connection.

The maximum magnetic flux density occurs between two electrodes of a classic bifilar pair at their closest approach to each other (Fig. 4, 1-1 and 1-2), which is entirely logical for the bifilar connection nature. At zero shift of phases, there are not any flows in the center of the computational domain and the magnetic field arrows form circles around each electrode as previously mentioned. The maximum intensity of magnetic flows was predicted for the case of the phase shift of $120^{\circ}$ between bifilar electrodes with the closest arrangement. A phase shift of $120^{\circ}$ (Fig. 4, variant 1-2) causes the crossflows between non-bifilar electrodes also, and the magnetic field vectors form closed circuits bordering electrodes of the adjacent phases two by two. It should be stated that for all considered cases with phases shift of $120^{\circ}$, the mentioned crossflow presents over the entire field of the simulated cross-section of the mould. This effect of current cross-flow should cause magnetodynamic rotation of a slag bath.

This phenomenon in the ESR process makes a positive effect on the laminar type of slag bath rotation, which may improve the thermal and chemical homogeneity of heat distribution in both the slag bath and metal pool. The turbulent vortexes break the flatness of the slag bath upper surface, making the furnace operation less stable. A stronger rotation of slag bath can involve underlying layers of a metal pool that increases the segregation of elements over ingot cross-section, which is especially dangerous for high alloyed steels and superalloys.

In the case of equal distance between all consumable electrodes (variants 2-1 and 2-2), the intensity of the magnetic flux between the bifilar and non-bifilar electrodes is the same. Still, magnetic flow arrows have the opposite directions. The phase shift of $120^{\circ}$ in this case increases magnetic field lines between adjacent phases, which also can cause magnetodynamic rotation of the slag bath. In general, the distribution of the electromagnetic field here is more uniform than in the case of the close location of the electrodes in a bifilar pair.

For 3-1 and 3-2 variants (expanded location of bifilar pair electrodes), the picture of magnetic fields is practically identical to variants $1-1$ and $1-2$. But the cross-flow here is going between non-bifilar electrodes, which is closer than electrodes of a bifilar pair. In these variants, unequal melting of electrodes in bifilar pair is expected, and the process control tends to be more difficult. In this case, for melting control in pairs, each electrode should be equipped by the separately regulated drive that complicates the ESR furnace operation. Thus, these two variants are excluded from further discussions.

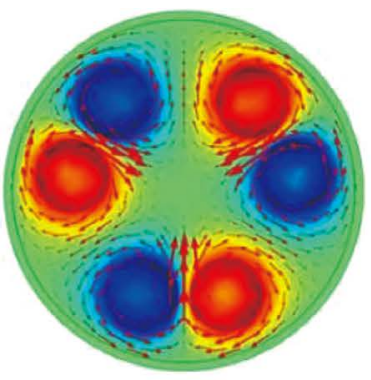

1-1

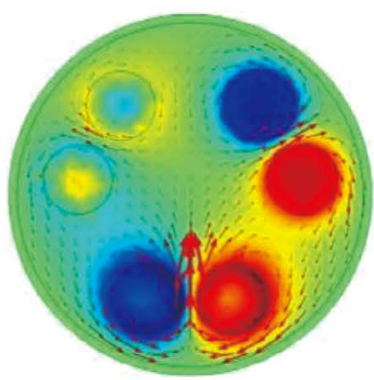

$1-2$

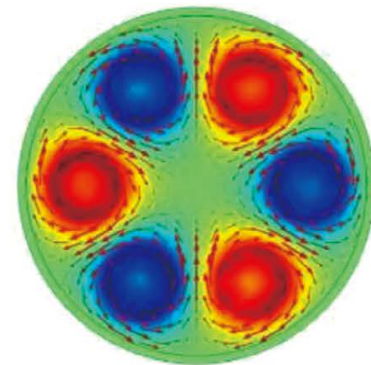

2-1

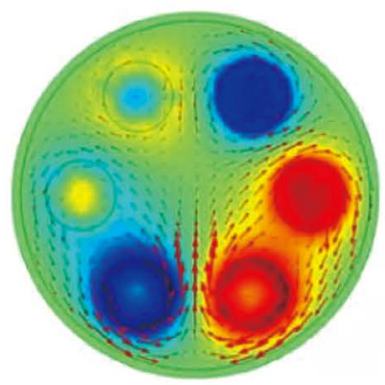

2-2

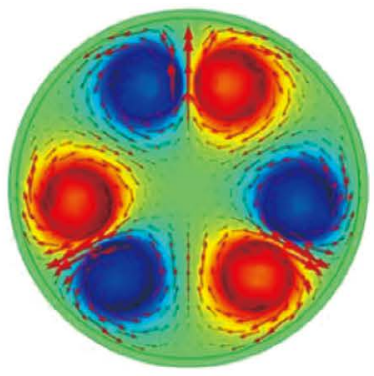

3-1

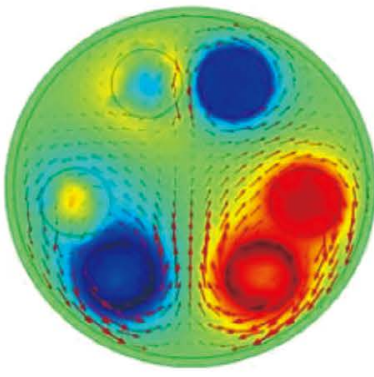

3-2

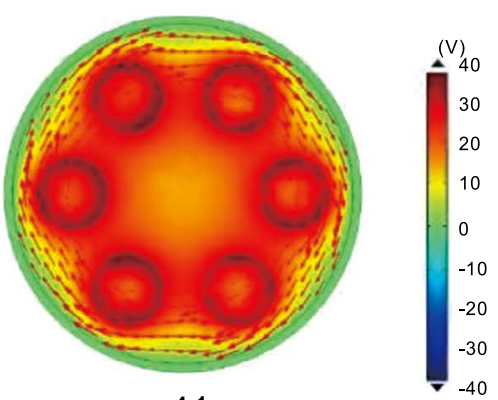

4-1

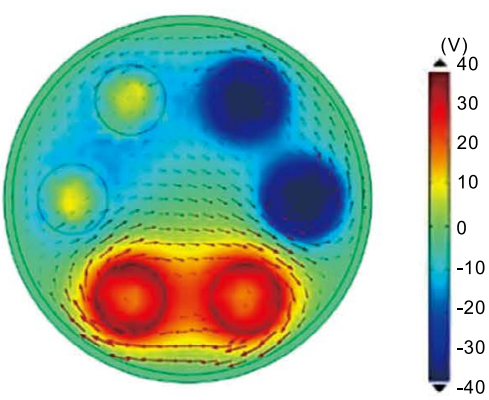

4-2

Fig. 4: Distribution of potential (given by colors) and magnetic flux density (shown by arrows) at simulated variants of consumable electrode locations and connections (according to Table 2) 
In the case of the monofilar connection of uniformly distributed electrodes and the same phase angle power supply (variant 4-1), the distribution of potential is the most uniform. The magnetic field makes close circuit bordering all electrodes together that will cause the slag bath rotation around the whole melting space of the mould. At pairwise connection to three single-phase power sources with phases shift of $120^{\circ}$, the picture looks more similar to the bifilar connection, because of the change in current intensity two by two. The positive difference from bifilar cases here is that two electrodes connected to a single-phase transformer have the same potential and a magnetic field exists in the center of the slag bath.

The Joule heat distribution for bifilar electrodes in pairs and equally distributed, as well as for monofilar connected equidistantly located electrodes were also calculated and results are given in Fig. 5.

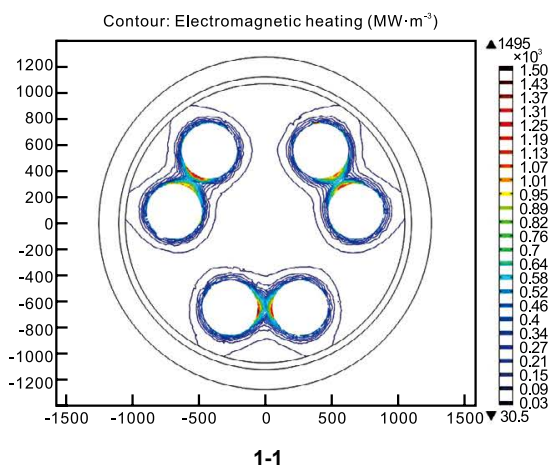

Contour: Electromagnetic heating $\left(M W \cdot \mathrm{m}^{-3}\right)$

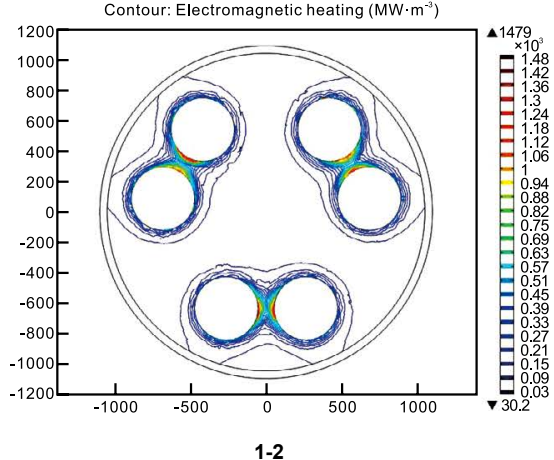

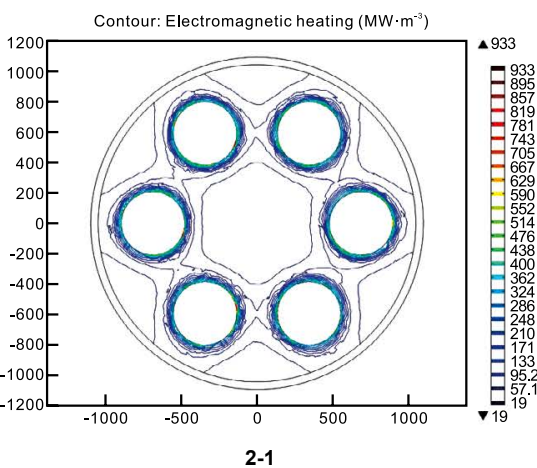

Contour: Electromagnetic heating $\left(\mathrm{MW} \cdot \mathrm{m}^{-3}\right)$

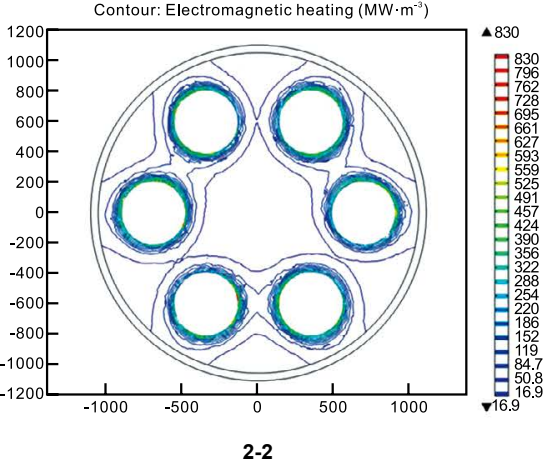

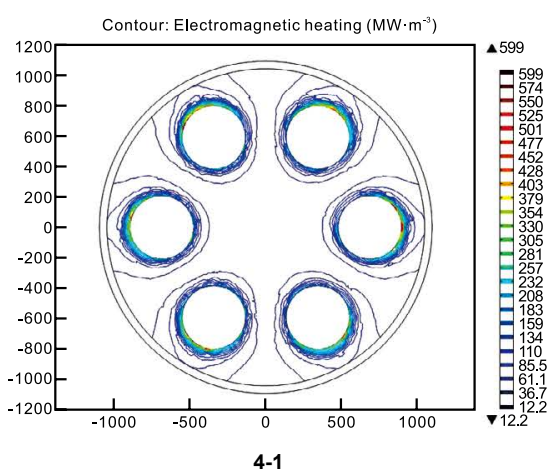

Contour: Electromagnetic heating $\left(\mathrm{MW} \cdot \mathrm{m}^{-3}\right)$

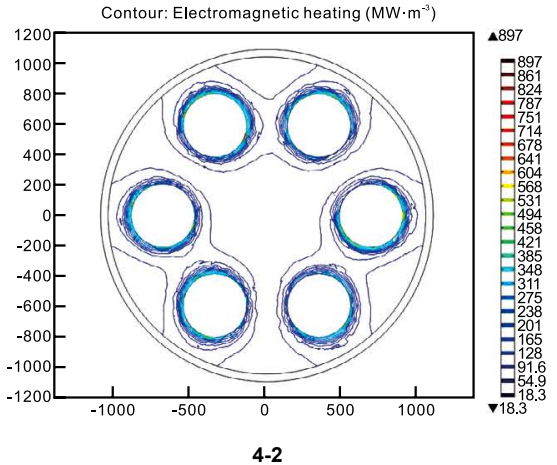

Fig. 5: Distribution of Joule heat release for the variants according to Table 2

The simulation shows that for the bifilar variants, the most heat generation is going between bifilar pair electrodes, and its intensity is greater when electrodes are located close to each other. The bifilar electrodes (variants1-1 and 1-2) in close location to each other produce the maximal amount of Joule heat in the slag bath.

This variant should be the best choice for a three-phase six electrodes furnace from the point of view of electrical efficiency and heat productivity. Despite the cross-flow between phases at the three-phase connection, the central volume of the slag bath is not heated enough to be visible on plotted images for all studied variants. In comparing heat release distribution with the images of the magnetic flux density and potential distribution in the slag bath (Fig. 4), it becomes evident that variants 1-1 and 1-2 provide the most efficient electroslag heating, but the less uniform distribution of heat fields. At the same time, variants 2-1 and 2-2 with the more symmetrical distribution of electromagnetic fields at the equidistant location of electrodes are less effective at heating productivity but provide more uniform heat distribution.

The monofilar multielectrode connection shows less heat productivity in comparison to both considered bifilar variants.
However, this kind of connection could make a better uniform potential distribution and favorable magnetic field, moreover, this is the best form from the point view of ingot quality. Further investigation will be focused on controlling the threephase bifilar ESR to improve the uniformity of electromagnetic fields and provide uniform melting and heat distribution at heavy forging ingots manufacturing.

\section{Conclusions}

According to the analysis, these conclusions are drawn:

(1) Under the three-phase bifilar diagram of power supply for the electroslag remelting, the geometrical location of electrodes in a mould is critically important.

(2) The phase shift can sufficiently affect the magnetic field vectors' direction and connect heat release intensity in a mould, which would change slag movement direction.

(3) The most intensive electromagnetic heating (Joule heat) predictably occurs between the closest located electrodes in a bifilar pair of one phase or non-bifilar electrodes of adjacent phases. 
(4) The equidistant location of electrodes at the usage of the bifilar connection gives a more uniform distribution of slag bath heating. Still, it is less effective from the point of view of process productivity.

(5) The nonuniformity of the Joule heat release under the tips of the electrodes in each bifilar pair reaches $20 \%$ at their equidistant location in the mould (Fig. 5 2-2) and increases to $40 \%$ in case of another location (Fig. 5 1-2).

(6) For the monofilar multielectrode diagram of three-phase connection without phase shift, the most uniform distribution of magnetic field vectors, potential, and heat generation is predicted, which makes this case the most promising from the point of view of ingot quality.

\section{References}

[1] Paton B, Medovar B, Latasch Y. Electric melting of highalloyed steels and alloys in the water-cooled mould. Bulleting of technical information. Moskow: Metallurgizdat, 1957: 7. (In Russian)

[2] Medovar B. Moscow: Metallurgizdat, 1963: 170. (In Russian)

[3] Liu X H, Wang J Q, Jia W G, et al. Simulation of electroslag re-melting process of $120 \mathrm{t}$ large ingot for nuclear power station and its application. China Foundry, 2011, 8(4): 413-417.

[4] Yin F X, Xiao Z X, Feng J H. et al. Effects of electrode configuration on electroslag remelting process of M2 highspeed steel ingot. China Foundry, 2019, 16(2): 126-134.

[5] Wang F, Li B K, Gao T Y. Analysis of electromagnetic field and temperature field in ESR process with three electrodes. In: Proceedings of the 8th Pacific Rim International Congress on Advanced Materials and Processing. The Minerals, Metals \& Materials Society, 2013: 3091-3098.

[6] Li B K, Gao T Y, Shan M L. Numerical analysis of electromagnetic field in an electroslag remelting process with three-phases electrodes. In: CFD Modeling and Simulation in Materials Processing. The Minerals, Metals \& Materials Society, 2012: 131-138.
[7] Ren N, Li B K, Li L M, et al. Numerical investigation on the fluid flow and heat transfer in electroslag remelting furnace with triple-electrode. Ironmaking \& Steelmaking, 2016, 45(2): 125-134

[8] Li Z B. Electroslag metallurgy principle and application. Beijing: Metallurgical Industry Press, 1996.

[9] Medovar L, Sybyr A, Stovpchenko G, et al. Investigation of the huge ESR hollow ingot quality. In: Proceedings of the Liquid Metal Processing \& Casting Conference 2015, 20-24 September 2015, Leoben (Austria), 2015: 95-103.

[10] Medovar L, Stovpchenko G, Fedorovskiy B. Slab furnacesexperience and requirements of the present. Modern Electrometallurgy, 2015, 2: 3-9. (In Russian)

[11] Medovar L. et al. Most recent development of the ESR hollow ingot technology \& equipment. In: Proc. of 19th Int. Forgemasters Meeting, Makuhari Messe Tokyo Bay Area, Japan, September 29 - October 3, 2014: 154-159.

[12] Sibaki E K, Kharicha A, Wu M, et al. A numerical study on the influence of the frequency of the applied $A C$ current on the electroslag remelting process. In: Proceedings of the 2013 International Symposium on Liquid Metal Processing \& Casting. The Minerals, Metals \& Materials Society, 2013: 1319.

[13] Bettoni P, Biebricher U, Franz $\mathrm{H}$, et al. Large ESR forging ingots and their quality in production. La Metallurgia Italiana, 2014, 106: 13-21.

[14] Roberts R J. Power supplies for electroslag furnaces: A preliminary comparison. Journal of Vacuum Science and Technology, 1970, 7(6): S81.

[15] Wang C Z, Song J C. Structure modification and constant remelting speed control of a 120-t three-phase electroslag furnace. China Foundry, 2012, 9(4): 370-375.

[16] Dilawari A H, Szekely J. A mathematical model of slag and metal flow in the ESR process. Metallurgical Transactions B, 1977, 8B: 227-236. 